\title{
Genome-wide association and transcriptome studies identify candidate genes and pathways for feed conversion ratio in pigs
}

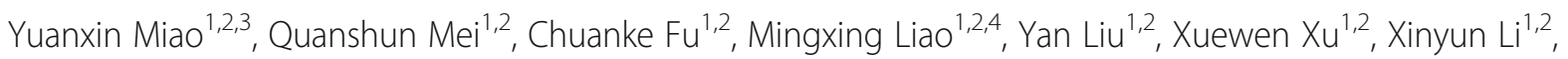
Shuhong Zhao ${ }^{1,2}$ and Tao Xiang ${ }^{1,2^{*}}$

\begin{abstract}
Background: The feed conversion ratio (FCR) is an important productive trait that greatly affects profits in the pig industry. Elucidating the genetic mechanisms underpinning FCR may promote more efficient improvement of FCR through artificial selection. In this study, we integrated a genome-wide association study (GWAS) with transcriptome analyses of different tissues in Yorkshire pigs (YY) with the aim of identifying key genes and signalling pathways associated with FCR.

Results: A total of 61 significant single nucleotide polymorphisms (SNPS) were detected by GWAS in YY. All of these SNPs were located on porcine chromosome (SSC) 5, and the covered region was considered a quantitative trait locus $(\mathrm{QTL})$ region for FCR. Some genes distributed around these significant SNPs were considered as candidates for regulating FCR, including TPH2, FAR2, IRAK3, YARS2, GRIP1, FRS2, CNOT2 and TRHDE. According to transcriptome analyses in the hypothalamus, TPH2 exhibits the potential to regulate intestinal motility through serotonergic synapse and oxytocin signalling pathways. In addition, GRIP1 may be involved in glutamatergic and GABAergic signalling pathways, which regulate FCR by affecting appetite in pigs. Moreover, GRIP1, FRS2, CNOT2, and TRHDE may regulate metabolism in various tissues through a thyroid hormone signalling pathway.

Conclusions: Based on the results from GWAS and transcriptome analyses, the TPH2, GRIP1, FRS2, TRHDE, and CNOT2 genes were considered candidate genes for regulating FCR in Yorkshire pigs. These findings improve the understanding of the genetic mechanisms of FCR and may help optimize the design of breeding schemes.
\end{abstract}

Keywords: GWAS, Transcriptomics, Feed conversion ratio, Pigs, Pathways, Hypothalamus

\footnotetext{
* Correspondence: Tao.Xiang@mail.hzau.edu.cn

${ }^{1}$ Key Laboratory of Agricultural Animal Genetics, Breeding and Reproduction of Ministry of Education \& Key Laboratory of Swine Genetics and Breeding of Ministry of Agriculture, Huazhong Agricultural University, Wuhan 430070, China

${ }^{2}$ The Cooperative Innovation Center for Sustainable Pig Production, Wuhan 430070, China

Full list of author information is available at the end of the article
}

(c) The Author(s). 2021 Open Access This article is licensed under a Creative Commons Attribution 4.0 International License, which permits use, sharing, adaptation, distribution and reproduction in any medium or format, as long as you give appropriate credit to the original author(s) and the source, provide a link to the Creative Commons licence, and indicate if changes were made. The images or other third party material in this article are included in the article's Creative Commons licence, unless indicated otherwise in a credit line to the material. If material is not included in the article's Creative Commons licence and your intended use is not permitted by statutory regulation or exceeds the permitted use, you will need to obtain permission directly from the copyright holder. To view a copy of this licence, visit http://creativecommons.org/licenses/by/4.0/ The Creative Commons Public Domain Dedication waiver (http://creativecommons.org/publicdomain/zero/1.0/) applies to the data made available in this article, unless otherwise stated in a credit line to the data. 
Improving the feed conversion ratio (FCR) has become an imperative for the pig industry $[1,2]$. FCR is influenced by many factors, such as metabolism, body composition and physical activity. Genetic effects must also be considered in improving FCR [1, 3, 4]. Artificial selection can effectively improve FCR, but this progress is time-consuming and expensive [5]. Therefore, elucidating the genetic mechanisms underpinning FCR and identifying genes that are significantly associated with FCR could enhance the efficiency of FCR improvement.

Genome-wide association analysis (GWAS) has previously been demonstrated as an effective method for detecting genetic variants and candidate genes associated with FCR [6-8]. Overall, a large number of singlenucleotide polymorphisms (SNPs) located on SSC 1, SSC 4, SSC 6, SSC 7 and SSC X have been identified as significantly associated with FCR. Additionally, some QTL regions and candidate genes have been reported to be associated with FCR through GWAS [9-12]. The marker WU_10.2_7_18377044 on SSC 7 has been reported to explain approximately $2.37 \%$ of phenotypic variance in residual feed intake (RFI), and DRGA0001676 on SSC 1 explained 3.22 and $5.46 \%$ of phenotypic variance in FCR and RFI, respectively [6]. Furthermore, QTL regions for RFI were detected on SSCs 1, 8, 9, 13 and 18 [8]. In addition, MC4R, XIRP2, TTC29, SOGA1, GRK5, PROX1, NMBR, KCTD16, ASGR1, PRKCQ, PITRM1 and TIAM1 have been reported as candidate genes for FCR in pigs by GWAS [9-12].

Transcriptome sequencing has also been comprehensively used to identify candidate genes and to elucidate the molecular mechanisms of FCR. The pathways of hormonal regulation, Notch signalling, and Wnt signalling in pituitary tissue have been reported to regulate FCR in pigs [13]. Additionally, VA metabolism, which can regulate fatty acid and steroid hormone metabolism in the liver tissue of pigs, has been found to be associated with FCR [14]. Moreover, in skeletal muscle tissue, genes involved in mitochondrial energy metabolism were downregulated, and genes involved in skeletal muscle differentiation and proliferation were upregulated, in the skeletal muscle tissues of pigs with low FCR [15]. Gradient boosting machine learning applied to muscle transcriptomes indicated that FKBP5, MUM1, AKAP12, FYN, TMED3, PHKB, TGF, SOCS6, ILR4, and FRAS1 were related to FCR in pigs [16]. Transcriptomes in caecal and colonic mucosal tissues indicated that energy and lipid metabolism can affected FCR and that GUCA2A, GUCA2B, HSP70.2, NOS2, PCK1, SLCs, and $C Y P S$ were negatively associated with FCR in pigs [17]. Although these studies have successfully identified some important signalling pathways and candidate genes in FCR, much remains to be clarified about the molecular mechanisms of FCR.
To our knowledge, few studies have integrated the results of GWAS and transcriptome analyses to identify the major genes and crucial signalling pathways of FCR in pigs. Thus, the objectives of our study were to identify QTLs and to unravel the genetic architecture of FCR in Yorkshire pigs by performing both GWAS and transcriptome analyses in pig tissues that are related to the progress of FCR. This integrated analysis may help to enhance the power and efficiency of identifying candidate genes and key signalling pathways of FCR in Yorkshire pigs.

\section{Results}

\section{Genome-wide association analyses for FCR}

In total, 61 SNPs reached the significance threshold of 5.796, which was calculated as the cut-off after Bonferroni correction $(=-\log 10(0.05 / 31326))$ (Fig. 1) [18]. All the significantly associated SNPs (61 SNPs) were located on SSC5. Among these SNPs, most (54 SNPs) are located within the region of $36.1-44.3 \mathrm{Mb}$ on SSC5, while 5 SNPs are located within the region of $47.1-47.8 \mathrm{Mb}$ and 2 SNPs are located within the region of $33.4 \sim 34.5$ $\mathrm{Mb}$.

\section{LD block, associated region analysis and candidate genes identified for FCR}

Several linkage disequilibrium (LD) blocks were detected in the regions where the 61 significantly associated SNPs were located: $3 \mathrm{LD}$ blocks were detected in the region of 33.4-34.5 Mb on SSC5; 3 LD blocks were detected in the region of $36.1-44.3 \mathrm{Mb}$ on SSC5, and $1 \mathrm{LD}$ block was detected in the region of $47.1-47.8 \mathrm{Mb}$ on SSC5 (Fig. 2). The 33.4-34.5 Mb, 36.1-44.3 Mb, and 47.1$47.8 \mathrm{Mb}$ regions on SSC5 maps in the Sscrofa 10.2 genome assembly were realigned to $30.2-31.3 \mathrm{Mb}, 33.6-$ $41.08 \mathrm{Mb}, 43.8-44.5 \mathrm{Mb}$ on SSC5 in the Sscrofa 11.1 genome assembly by NCBI Remap. Then, PigQTLdb [19] was used to identify QTLs in these regions, and the results showed that these regions contained QTLs regulating the traits of days to $110 \mathrm{~kg}$, feed intake, average daily gain, body weight, loin percentage, intramuscular fat content, average backfat thickness, etc. (Table S1). Feed intake and growth traits are tightly related to the performance FCR. Thus, these regions were also considered crucial QTL regions associated with FCR.

All detailed information on the significantly associated SNPs identified by GWAS and the putative candidate genes in this QTL region is shown in Table S2. Among the 61 identified significantly associated SNPs, 26 SNPs were located within different genes. These significant SNPs, together with their corresponding genes, are shown in Table 1. Several other genes located in the 0.5 $\mathrm{Mb}$ genome region flanking the significantly associated SNPs were also considered candidate genes, including fibroblast growth factor receptor substrate 2 (FRS2), 


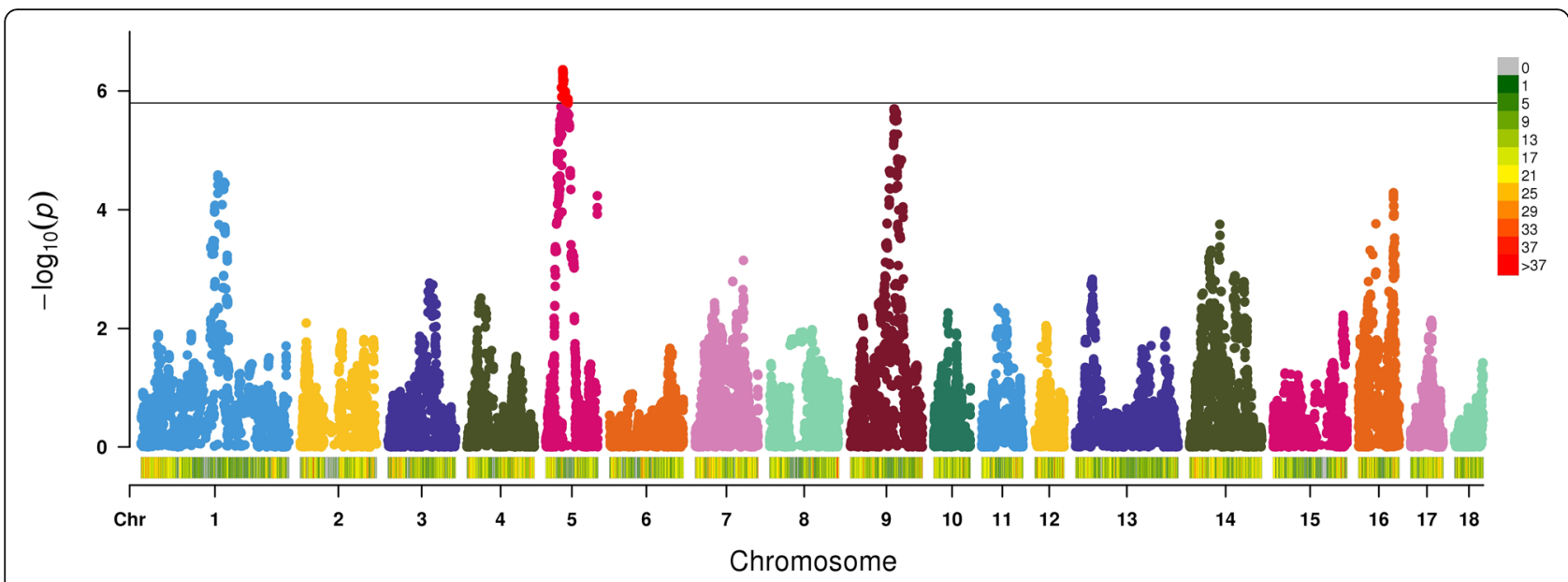

Fig. 1 Manhattan plot of genome-wide associated analysis studies for FCR. The solid line indicates a Bonferroni corrected $p$-value $=5.796$

tryptophan hydroxylase 2 (TPH2), thyrotropin releasing hormone degrading enzyme (TRHDE), GLI pathogenesis related 1 (GLIPR1) and fatty acyl-CoA reductase 2 (FAR2). The ISwine platform [20] was also used to identify candidate genes for FCR in pigs. All the candidate genes identified by the ISwine platform are shown in Table S3. Based on the results from ISwine, the TRHDE, TPH2, FAR2, FRS2, and GLIPR1 genes were confirmed as candidate genes for regulating FCR in Yorkshire pigs.

\section{Integration of GWAS and transcriptome analyses}

To clarify the genetic mechanisms involved in the regulation of FCR in pigs, we integrated the GWAS results with previously published FCR transcriptome data by using DAVID [21]. The discovered signalling pathways and possible major genes are shown in Fig. 3. A mutation in the TPH 2 gene may influence the expression of the neurotransmitter serotonin $(5-\mathrm{HT})$, which mediates colonic motility by the secretion of hypothalamic oxytocin (Fig. 3a, Table 2). In addition, a mutation in the GRIP1 gene may influence the aggregation of GABA and glutamate, which mediates appetite in pigs (Fig. 3cc,
Table 2). Notably, several genes involved in the regulation of thyroid hormone signalling, namely, GRIP1, FRS2, CNOT2, and TRHDE, were significantly differentially expressed in pigs with high or low FCR. The thyroid hormone signalling pathway participates in the regulation of metabolism in various tissues (Fig. 3b, Table 2). All detailed information on the differentially expressed genes identified by RNA-seq in different tissues is shown in Table S5, S6, S7 and S8.

\section{Discussion}

QTLs, LD blocks and candidate genes for FCR

Feed efficiency (FE) is an important economic trait that greatly affects the economic profit of the breeding industry. The identification of major genes regulating FE may help to enhance the efficiency of improving FE through molecular breeding technology. However, only a few candidate genes have been identified due to the difficulty of analysing ratio traits and to sample size limitation. In the current study, we implemented a genome-wide association analysis for FCR in a large Yorkshire population. Our analyses identified a series of novel significant SNPs

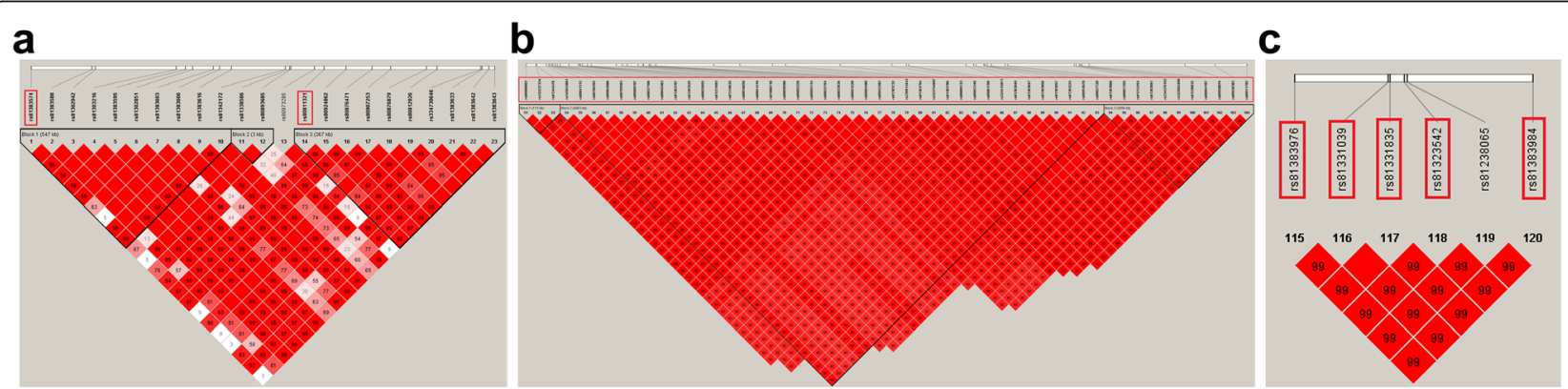

Fig. 2 Linkage disequilibrium block on chromosome 5. Markers in the block are shown in bold. a Linkage disequilibrium block detected in the regions from 33.4 to $34.5 \mathrm{Mb}$ on SSC5, b Linkage disequilibrium block detected in the regions from 36.1 to $44.3 \mathrm{Mb}$ on SSC5, c Linkage disequilibrium block detected in the regions from 47.1 to $47.8 \mathrm{Mb}$ on SSC5. SNPs in red boxes are significantly associated with FCR 
Table 1 Summary of within-gene significant SNPs for FCR trait

\begin{tabular}{lllll}
\hline SNP ID & bp (SSC10.2) & bp (SSC11.1) & Pvalue & Genes \\
\hline rs80841312 & $36,496,185$ & $33,897,913$ & $4.39 E-07$ & CCT2 \\
rs80786392 & $36,510,853$ & $33,912,700$ & $4.51 E-07$ & BEST3 CCT2 \\
rs80837106 & $36,589,679$ & $33,991,092$ & $4.51 \mathrm{E}-07$ & CCT2 \\
rs80845463 & $36,621,274$ & $34,022,700$ & $4.51 \mathrm{E}-07$ & CCT2 \\
rs81383707 & $36,721,314$ & $34,122,773$ & $4.54 \mathrm{E}-07$ & MYRFL \\
rs80964888 & $36,532,511$ & $33,934,311$ & $4.72 \mathrm{E}-07$ & BEST3 CCT2 \\
rs332237334 & $36,353,885$ & $33,842,149$ & $4.79 \mathrm{E}-07$ & FRS2 \\
rs81344478 & $36,357,722$ & $33,838,344$ & $4.79 \mathrm{E}-07$ & FRS2 \\
rs80850598 & $37,318,776$ & $34,747,588$ & $4.93 \mathrm{E}-07$ & PTPRB \\
rs81287625 & $36,826,851$ & $34,177,721$ & $5.25 \mathrm{E}-07$ & MYRFL \\
rs345043801 & $36,469,745$ & $33,871,482$ & $6.03 \mathrm{E}-07$ & CCT2 \\
rs80785563 & $36,544,839$ & $33,946,621$ & $6.03 \mathrm{E}-07$ & BEST3 CCT2 \\
rs80989707 & $36,568,996$ & $33,970,407$ & $6.35 \mathrm{E}-07$ & CCT2 \\
rs339913443 & $38,629,120$ & $35,929,672$ & $6.61 \mathrm{E}-07$ & TPH2 \\
rs80835055 & $36,838,800$ & $34,189,654$ & $7.00 \mathrm{E}-07$ & MYRFL \\
rs81000718 & $37,249,647$ & $34,677,764$ & $7.01 \mathrm{E}-07$ & PTPRB \\
rs80892229 & $37,369,531$ & $34,769,398$ & $7.44 \mathrm{E}-07$ & PTPRB \\
rs323754097 & $39,138,147$ & $36,346,640$ & $9.75 \mathrm{E}-07$ & TRHDE \\
rs81383732 & $38,337,110$ & $35,634,440$ & $1.01 \mathrm{E}-06$ & ZFC3H1 \\
rs80811321 & $34,095,144$ & $30,820,701$ & $1.26 \mathrm{E}-06$ & GRIP1 \\
rs81323542 & $47,441,081$ & $44,096,325$ & $1.37 \mathrm{E}-06$ & TMTC1 \\
rs81212454 & $42,358,084$ & $38,794,710$ & $1.46 \mathrm{E}-06$ & GLIPR1 KRR1 \\
rs81383891 & $42,378,400$ & $38,815,027$ & $1.46 \mathrm{E}-06$ & GLIPR1 KRR1 \\
rs81331039 & $47,398,882$ & $44,127,767$ & $1.49 \mathrm{E}-06$ & TMTC1 \\
rs81331835 & $47,404,818$ & $44,121,830$ & $1.49 \mathrm{E}-06$ & TMTC1 \\
rs81383984 & $47,782,626$ & $44,464,360$ & $1.58 \mathrm{E}-06$ & FAR2 \\
\hline & & & &
\end{tabular}

located in the $33.4-34.5 \mathrm{Mb}, 36.1-44.3 \mathrm{Mb}$, and $47.1-$ $47.8 \mathrm{Mb}$ regions on SSC5. LD analysis showed that these regions are highly linked, and many QTLs related to feed intake and growth traits are located in these regions. Logically, these regions were considered candidate QTL regions for FCR. Genes located within $1 \mathrm{Mb}$ of the significantly associated SNPs, including fatty acyl CoA reductase 2 (FAR2), interleukin-1 receptor-associated kinase-3 (IRAK3), and tyrosyl-tRNA synthetase 2 (YARS2), were inferred as candidate genes regulating FCR in our study.

The FAR2 gene spans $44.38 \mathrm{Mb}$ to $44.55 \mathrm{Mb}$ on SSC5. It is a key gene for fatty acid $\beta$-oxidation, acetyl-CoA translocation, peroxisome biogenesis, and the glyoxylate cycle [22]. Moreover, FAR2 was associated with insulin resistance [23]. Previous studies reported that lipid metabolism can explain the variation in FCR [14, 24, 25]. Therefore, the FAR2 gene might be a candidate gene for FCR.

IRAK3 belongs to the serine-threonine kinases family and is negatively correlated with the mitochondrial oxidative stress marker SOD2. It has been reported that high IRAK3 and low SOD2 cause weight loss [26, 27]. Previous studies reported that decreased IRAK3 was associated with increased mitochondrial reactive oxygen species (ROS) [28], and other studies have reported that ROS can decrease muscle mass by regulating mitochondrial biogenesis and the expression of antioxidant genes [29, 30]. Mitochondrial energy metabolism is a factor potentially affecting the feed conversion ratio in pigs [15]. Therefore, IRAK3 is worthy of further functional investigation.

YARS2 is a key factor that binds tyrosine to its corresponding mt-tRNA for the synthesis of mitochondrial proteins. Mutations in YARS2 can lead to mitochondrial respiratory chain complex deficiencies and are related to mitochondrial myopathy [31, 32]. YARS2 has not been functionally characterized in pigs. However, since its

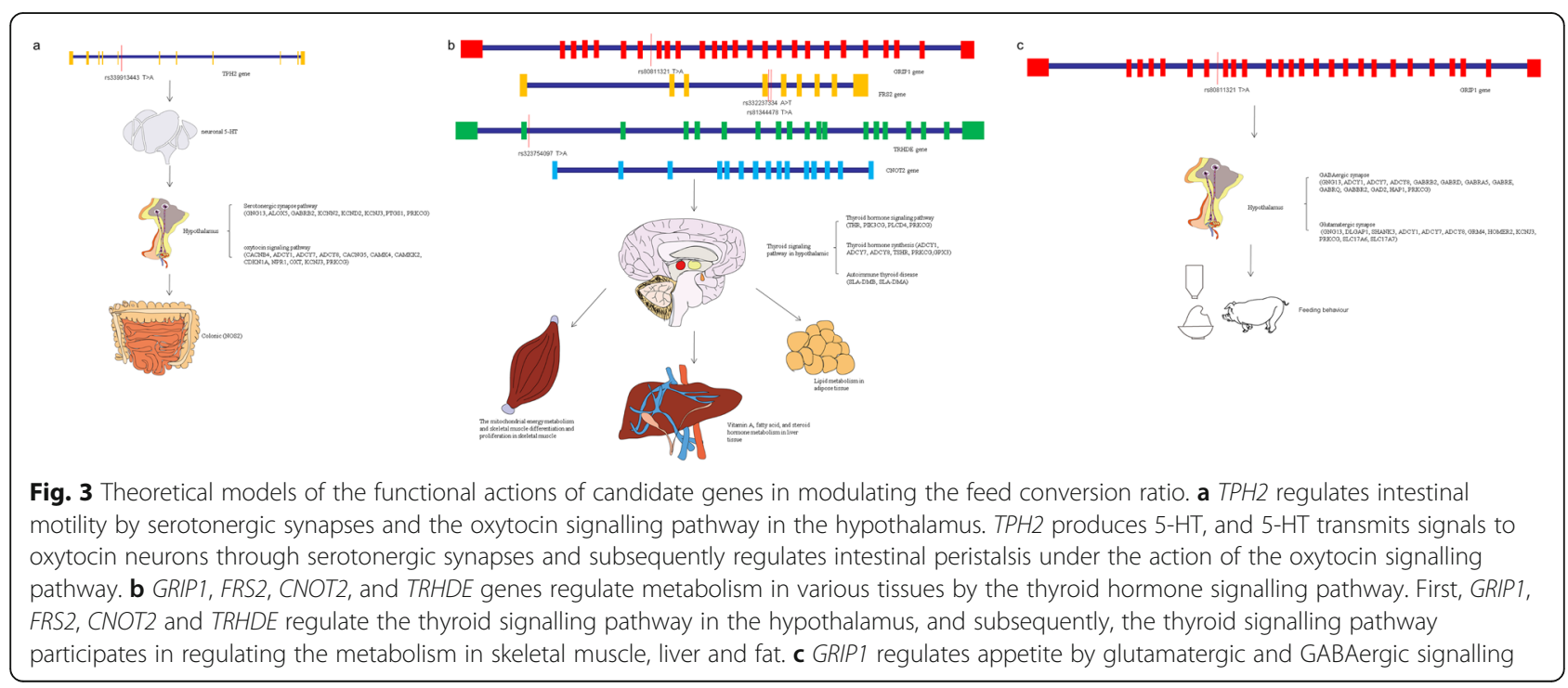


Table 2 Summary of identified pathways, DEGs and genes with significant SNPs

\begin{tabular}{|c|c|c|c|c|c|}
\hline \multirow[t]{2}{*}{ SNP ID } & \multirow{2}{*}{$\begin{array}{l}\text { Candidate } \\
\text { Gene }\end{array}$} & \multicolumn{3}{|l|}{ Pathway } & \multirow[t]{2}{*}{ Differentially expressed genes } \\
\hline & & Pathway name & P-Value & FDR & \\
\hline \multirow[t]{2}{*}{ rs80811321 } & \multirow[t]{2}{*}{ GRIP1 } & GABAergic synapse & $1.1 \mathrm{E}-6$ & $2.4 \mathrm{E}-5$ & $\begin{array}{l}\text { GNG13,ADCY1,GABRB2, ADCY8, ADCY7,GABRD,GABRE,GABRQ,GABBR2, } \\
\text { GAD2,HAP1,PRKCG }\end{array}$ \\
\hline & & Glutamatergic synapse & 4.0E-7 & $1.3 \mathrm{E}-5$ & $\begin{array}{l}\text { GNG13,DLGAP1,SHANK3, } \\
\text { ADCY1,ADCY8,ADCY7,GRM4, } \\
\text { HOMER2,KCNJ3,PRKCG,SLC17A6,SLC17A7 }\end{array}$ \\
\hline \multirow[t]{2}{*}{ rs339913443 } & \multirow[t]{2}{*}{$\mathrm{TPH} 2$} & Serotonergic synapse & $1.6 \mathrm{E}-3$ & $1.2 \mathrm{E}-2$ & ALOX5,GABRB2,KCNN2,KCND2,KCNJ3,PTGS1,PRKCG \\
\hline & & Oxytocin signaling pathway & $1.2 \mathrm{E}-4$ & $1.6 \mathrm{E}-3$ & $\begin{array}{l}\text { ADCY1,ADCY8,ADCY7,CACNG5,CAMK4,CAMKK2,CDKN1A,NPR1,OXT, } \\
\text { KCNJ3,PRKCG,CACNB4, }\end{array}$ \\
\hline \multirow{3}{*}{$\begin{array}{l}\text { rs80811321 } \\
\text { rs332237334 } \\
\text { rs81344478 } \\
\text { rs323754097 }\end{array}$} & \multirow{3}{*}{$\begin{array}{l}\text { GRIP1 } \\
\text { FRS2 } \\
\text { FRS2 } \\
\text { TRHDE } \\
\text { CNOT2 }\end{array}$} & Thyroid hormone synthesis & $1.8 \mathrm{E}-2$ & $8.0 \mathrm{E}-2$ & ADCY1,ADCY8,ADCY7,GPX3,PRKCG,TSHR, \\
\hline & & $\begin{array}{l}\text { Thyroid hormone signaling } \\
\text { pathway }\end{array}$ & $3.4 \mathrm{E}-1$ & $6.7 \mathrm{E}-1$ & TRH,PIK3CG,PLCD4,PRKCG, \\
\hline & & Autoimmune thyroid disease & 8.1E-1 & 8.2E-1 & SLA-DMB,SLA-DMA \\
\hline
\end{tabular}

*CNOT2: There were no significant SNP located within the gene, but there were significant SNPs located in the upstream and downstream of the gene

function involves mitochondrial protein synthesis and mitochondrial respiration, it might be an important candidate gene for FCR in pigs.

\section{GRIP1 controls appetite through glutamatergic and GABAergic signalling}

In this study, we integrated GWAS results with transcriptome analyses, aiming at identify candidate genes and biological pathways associated with FCR in pigs. Feed intake is a major physiological process associated with variations in FCR [33-35]. GABA ( $\gamma$-amino-butyric acid) and glutamate, which are expressed in hypothalamic neurons, can promote feeding and weight gain, while GRIP1 can interact with the C termini of AMPA receptors and cluster at both glutamatergic and GABAergic synapses [36-38]. In addition, genes associated with GABAergic synapse (GNG13, $A D C Y 1, A D C Y 7$, $A D C Y 8, G A B R B 2, G A B R D, G A B R A 5, G A B R E, G A B R Q$, GABBR2, GAD2, HAP1, PRKCG) and glutamatergic synapse (DLGAP1, SHANK3, ADCY1, ADCY7,ADCY8, GNG13, GRM4, HOMER2, KCNJ3, PRKCG, SLC17A6, SLC17A7) were differentially expressed in hypothalamic tissue in pigs with high or low FCR performance [39]. Therefore, GRIP1 may control appetite through glutamatergic (Fig. 4a) and GABAergic signalling pathways (Fig. 4b). Moreover, two informative SNPs in GRIP1 were identified to be significantly associated with backfat thickness in pigs [40]. Therefore, GRIP1 may be an important candidate gene for FCR in pigs.

TPH2 may affect 5-HT secretion, thereby mediating intestinal motility through the hypothalamic oxytocin signalling pathway

Brain-gut interactions may be an important factor in FCR in pigs [41]. The central neurotransmitter serotonin (5-hydroxytryptamine, 5-HT), produced by tryptophan hydroxylase 2 (Tph2), mediates colonic motility by regulating oxytocin (OT) synthesis in the hypothalamus $[42,43]$. In addition, knockout of TPH2 in mice resulted in depletion of 5-HT in the brain, and the mice showed increased food consumption [44]. Therefore, TPH2 can regulate appetite and intestinal motility by affecting the secretion of 5-HT. In our results, a significant SNP (rs339913443) was found to be located in the TPH2 gene. Moreover, transcriptome sequencing in the hypothalamus of pigs with extremely high or low feed efficiency revealed that genes related to serotonergic synapse (GNG13, ALOX5, GABRB2, KCNN2, KCND2, KCNJ3, PTGS1, PRKCG) (Fig. 5a) and the oxytocin signalling pathway $(A D C Y 1, A D C Y 7, A D C Y 8, C A C N G 5$, CAMK4, CDKN1A, CACNB4, CAMKK2, NPR1, OXT, $K C N J 3, P R K C G$ ) (Fig. $5 \mathrm{~b}$ ) were differentially expressed [39]. RNA-seq in the caecal and colonic mucosa revealed that NOS2, which is related to gastrointestinal peristalsis, was a candidate gene for FCR [17]. Therefore, the SNPs within TPH2 may change the expression of this gene, thereby affecting the secretion of 5-HT. Sequentially, 5HT regulates intestinal motility through the oxytocin signalling pathway in the hypothalamus.

\section{GRIP1, FRS2, CNOT2, TRHDE may affect metabolic processes}

Thyroid hormone $(\mathrm{TH})$, which is regulated by thyrotropin releasing hormone (TRH) and thyroid stimulating hormone (TSH), is in turn involved in regulating many metabolic processes essential for growth and development, including basal metabolic rate, facultative thermogenesis, skeletal muscle growth, regulation of body weight, and lipid metabolism [45-47]. Thyroid hormone receptors (TRs) mediate the biological effects of thyroid hormone (T3) [48]. In our study, many candidate genes participated in regulating TH signalling, including GRIP1, FRS2, CNOT2, and TRHDE. Among them, GRIP1 acts as a coactivator for $\mathrm{TR}$, strengthening the combination of TR and TH $[49,50]$. 


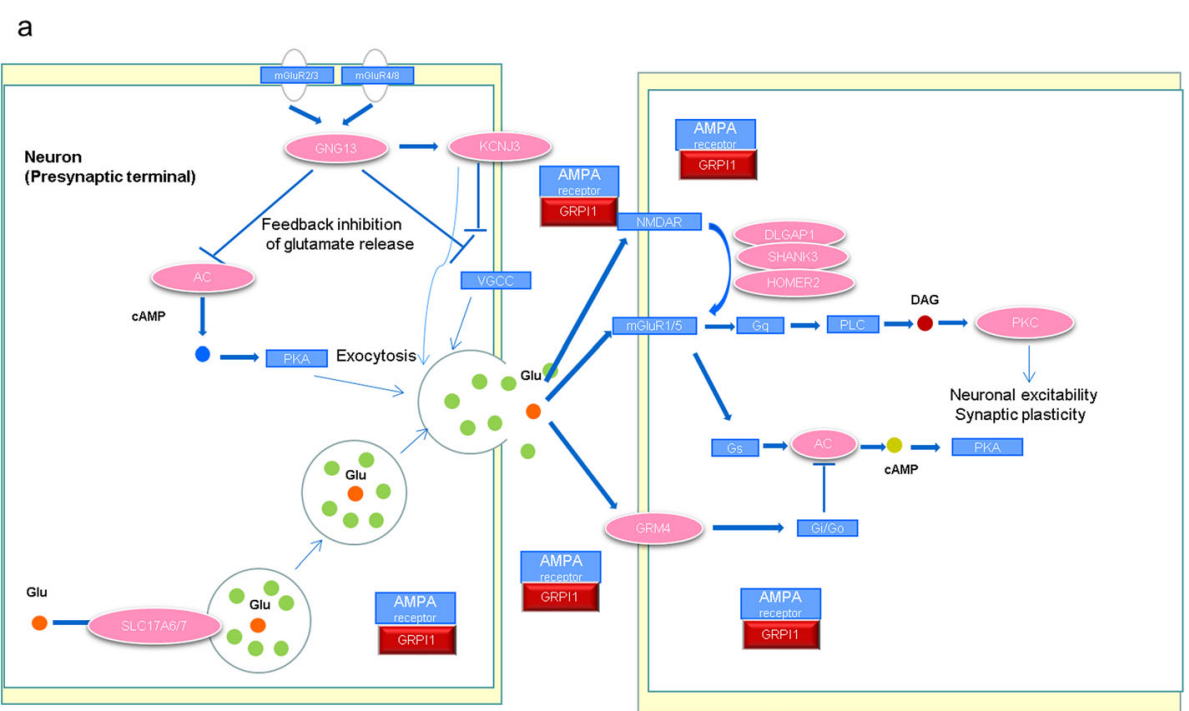

Glutamatergic synapse

b

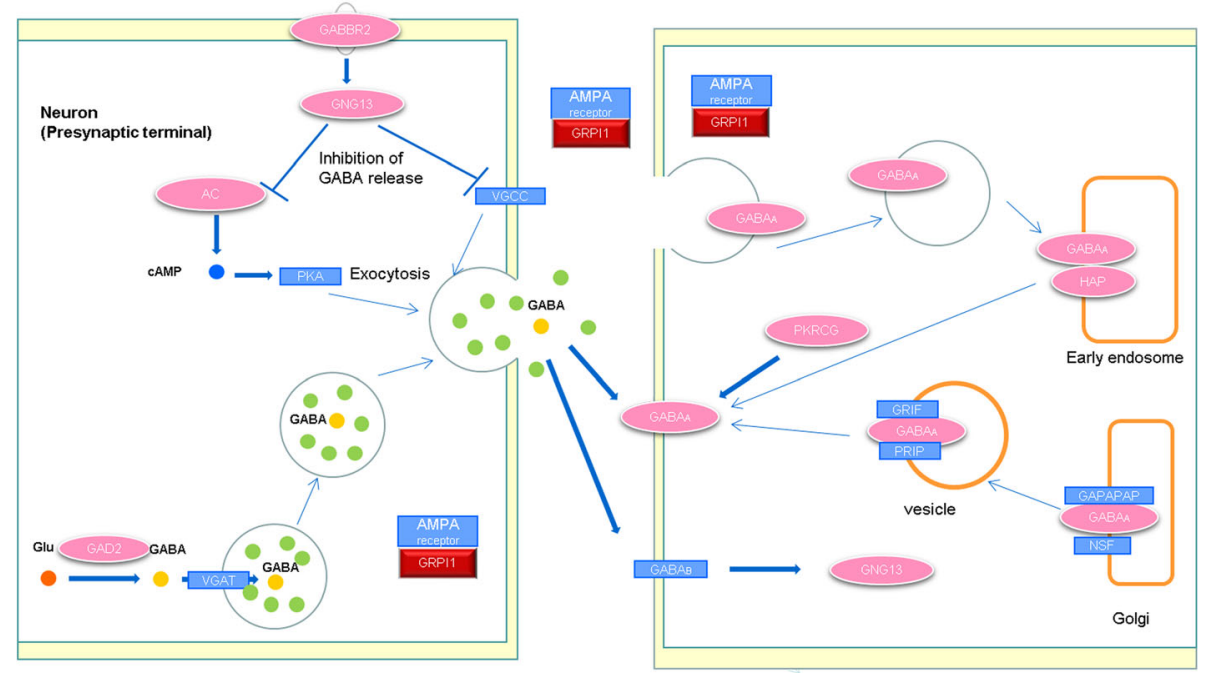

GABAergic synapse

Candidate gene

identified by GWAS

Differentially

expressed genes

Fig. 4 GRIP1 regulates appetite through glutamatergic synapses (a) and GABAergic synapses (b)

FRS2 is involved in FGF21-AMPK signalling and can be induced to accelerate energy metabolism through thyroid hormone [51]. CNOT2 is an important regulator of energy metabolism, cellular stress and fatty acid metabolism in skeletal muscles. The heterozygous intragenic deletion of CNOT2 displayed disordered phenotypes including learning disabilities, developmental delays, and hypothyroidism $[52,53]$. TRHDE is an extracellular peptidase that specifically degrades $T R H$ to regulate appetite and metabolism
$[54,55]$. SNP association analysis in a new Ujumqin Sheep population showed that the TRHDE gene was significantly associated with body weight [56]. Moreover, transcriptome sequencing in the hypothalamus of pigs with high or low FCR revealed that genes involved in the thyroid hormone signalling pathway (TRH, PIK3CG, PLCD4, PRKCG), thyroid hormone synthesis ( $A D C Y 1, A D C Y 7, A D C Y 8, G P X 3$, $P R K C G, T S H R$ ) and autoimmune thyroid disease (SLADMB, SLA-DMA) were differentially expressed [39]. 


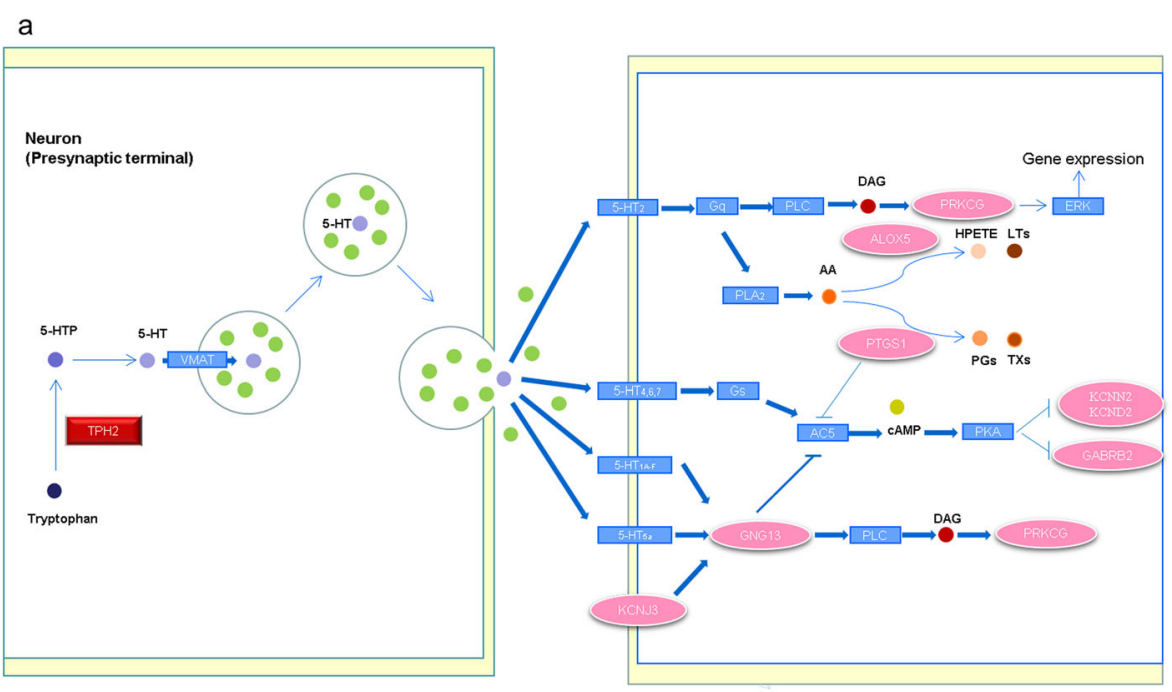

Serotonergic synapse pathway

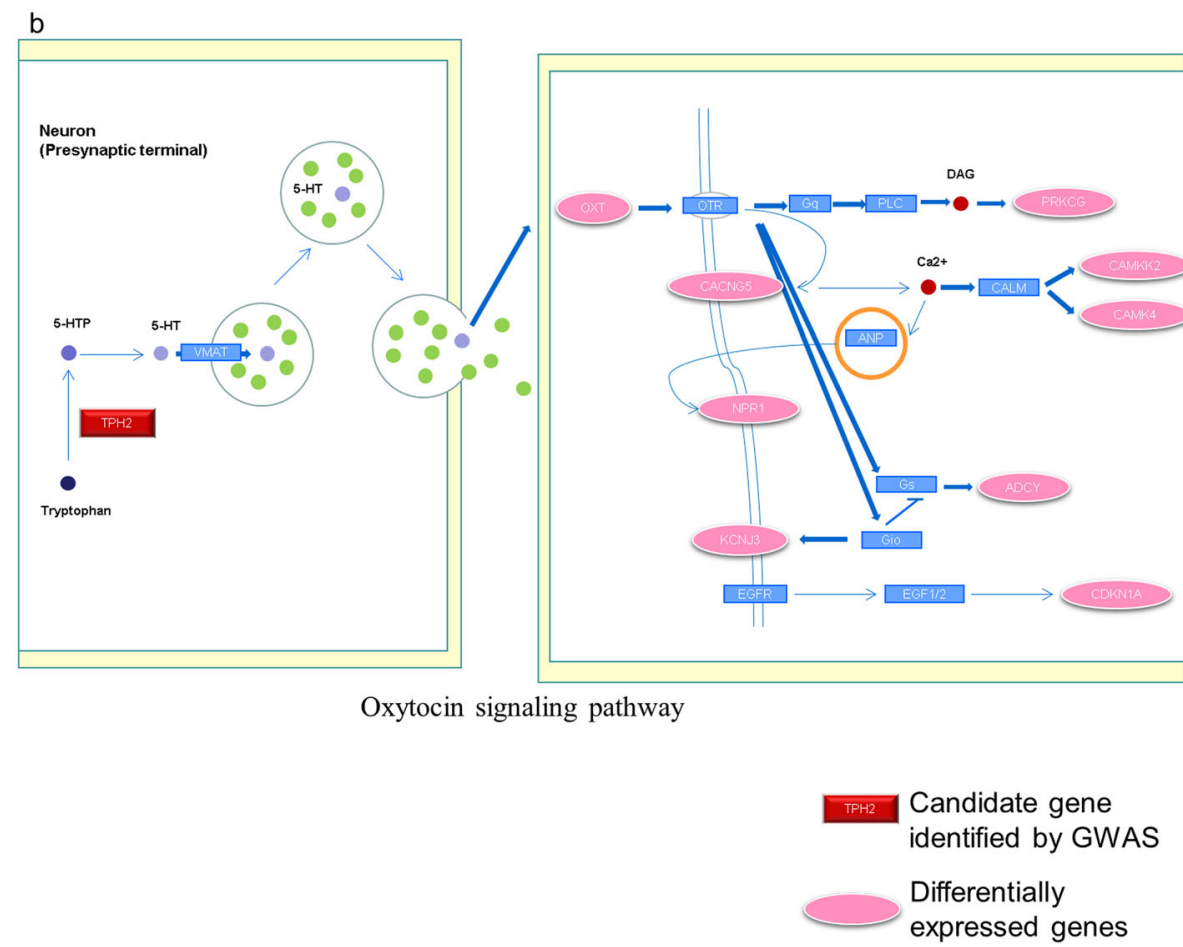

Fig. 5 5-HT, produced by $T P H 2$, regulates the serotonergic synapse pathway (a) and oxytocin signalling pathway (b) in the hypothalamus

Therefore, differences of FCR in pigs were mediated by the thyroid signalling pathway in the hypothalamus, leading to different phenotypes and differential gene expression in muscle, fat, liver and others tissues.

Overall, this study used GWAS to discover SNPs significantly associated with FCR. None of the significant sites changed the corresponding protein coding, but this study found that the downstream genes in the pathway were significantly differentially expressed in the high-FE and low-
FE groups. These results indicate that the SNPs found in this study may play a regulatory role. However, this possibility needs to be verified with other omics data in the future. To further confirm the causal genes, integration analyses of GWAS and eQTLs should be implemented.

\section{Conclusions}

The present study detected a novel QTL region on SSC5 that is significantly associated with FCR in Yorkshire 
pigs. An integrative analysis of the GWAS results and transcriptome results in different tissues has been used to identify candidate genes and signalling pathways that play a decisive role in this trait. GRIP1, TPH2, FRS2, CNOT2, and TRHDE were suggested to be the most likely candidate genes for FCR. These findings offer a better understanding of the molecular mechanisms regulating FCR in pigs.

\section{Materials and methods}

\section{Phenotype recordings}

In this study, all FCRs (feed intake/weight gain) were measured at intervals of 30 to $100 \mathrm{~kg}$ in Yorkshire pigs by a pig performance testing system in a national pig nucleus herd. In total, FCR recordings were collected from 14,401 pigs. All of the phenotypic recordings were measured between 2017 and 2020. Pedigrees can be traced back for ten generations. In total, 19,811 pigs are included in the pedigree. Genomic selection was started later in 2018, and since then ear tissues were collected following a criteria that at least 2 males and 2 females in each litter should be collected. As a result, 3672 YY pigs contained both FCR recordings and ear tissue samples. All experimental protocols were approved by the Ethics Committee of Huazhong Agricultural University (HZAUMU2013-0005).

\section{Genotypes}

The SNP markers were genotyped in $3672 \mathrm{YY}$ pigs by using an Illumina PorcineSNP60 Genotyping BeadChip. SNPs were mapped to pig chromosomes using Sscrofa genome build 10.2 [57]. Quality controls were applied as follows: Samples with call rates lower than $90 \%$ were removed, SNPs with call rates smaller than $90 \%$ were removed, and SNPs with minor allele frequencies smaller than 0.05 were filtered out; SNPs that deviated strongly from Hardy-Weinberg equilibrium within breeds $(p<$ $10^{-7}$ ) were also excluded. After quality control, $3672 \mathrm{YY}$ pigs and 31,236 SNPs distributed over the 18 porcine autosomes were used for genome-wide association analysis.

\section{Statistical model for the prediction of genomic breeding values}

The single-step GBLUP (ssGBLUP) method was used to predict genomic breeding values (GEBVs) [58, 59]:

$$
\mathbf{y}=\mathbf{X b}+\mathbf{Z u}+\mathbf{e}
$$

where y contained phenotypic recordings for FCR; Xb indicated the fixed effects, including unit-year-month effect, sex effect and covariate for the starting weight; $\mathbf{u}$ was random additive effect and $\mathbf{Z}$ was the incidence matrix to relate the additive effects to the phenotypic recordings; and e was a vector of residual effects. It was assumed that the random additive effects followed a normal distribution, as follows: $\mathbf{u} \sim N\left(0, \boldsymbol{H} \sigma_{u}^{2}\right)$, where $\boldsymbol{H}$ was the combined pedigree and genomic information relationship matrix [58].

To remove the contribution of information from relatives, de-regressed estimated breeding values (DEBVs) were used as the response variable in GWAS analysis [60], which can be calculated by weighting EBVs [61]. The weighting factor $\left(w_{i}\right)$ for animal i can be calculated as follows:

$$
w_{i}=\frac{1-h^{2}}{\left(c+\left[\left(1-r_{i}^{2}\right) /\left(r_{i}^{2}\right)\right]\right) h^{2}}
$$

where $h^{2}$ is the heritability of the trait, $r_{i}^{2}$ is the reliability of EBV of the ith animal, and $c$ is the proportion of genetic variation that could not be explained by the genetic information. In this study, c was assumed to be constant at 0.5 [62].

\section{Genome-wide association studies}

The genome-wide association study was performed on 3672 genotyped pigs by using the MLMA (mixed linear model-based association analysis) option in GCTA software [63]. All SNPs were used for the association analysis. The mixed linear model was:

$$
\mathbf{y}=\mathbf{1} \mu+\mathbf{x b}+\mathbf{w g}+\mathbf{e}
$$

where $y$ was the vector of DEBVs for FCR in the genotyped Yorkshire pigs; $\mu$ was the overall mean and $\mathbf{1}$ was a vector of ones; $\mathbf{x}$ was a vector of SNP genotypes, with entries $0,1,2$ for genotypes $\mathrm{AA}, \mathrm{AB}$ and $\mathrm{BB}$, respectively; $\mathrm{b}$ was the fixed additive genetic effect of analyzed SNP; and $\mathbf{g}$ was a vector of random polygenic effects and $\mathbf{w}$ was the incidence matrix relating the DEBVs to the corresponding random polygenic effects; It was assumed that $\mathbf{g}$ followed a normal distribution with mean of 0 and variance of $\boldsymbol{A} \sigma_{g}^{2}$, where $\boldsymbol{A}$ was the pedigreebased additive relationship matrix. $\mathbf{e}$ is a vector of residual effects, following a normal distribution as $\mathbf{e} \sim N$ ( $\left.0, \boldsymbol{D} \sigma_{e}^{2}\right)$, where $\boldsymbol{D}$ is a diagonal matrix with elements $d_{i i}$ $=\left(1-r_{D E B V}^{2}\right) / r_{D E B V}^{2}$ and $r_{D E B V}^{2}$ is the reliability of the DEBVs. A significant test of SNP effects was implemented by a two-sided t-test. Bonferroni corrections were set for the genome-wide significance threshold $(-\log 10[0.05 /$ number of SNPs $]=5.796)$.

\section{Detection of LD block and QTL analysis}

Significant SNPs located within $1 \mathrm{Mb}$ from each other were considered to belong to the same QTL region. Detection of LD blocks was performed in the chromosomal regions containing the identified significantly associated SNPs by Haploview software [64]. NCBI Remap was 
used to transfer the significant regions on SSC5 aligned to the Sscrofa 10.2 genome assembly to those aligned to the Sscrofa 11.1 genome assembly, since the original genomic information was mapped to SusScrofa 10.2 reference genome by the gene-sequenceing company. Then, QTLs located in these significant regions were identified by searching a pig QTL database (pigQTLdb, https://www.animalgenome.org/cgi-bin/QTLdb/SS/ index).

\section{Candidate gene search and integrated analysis with transcriptome data}

Genes that are located in the identified QTL region and the $0.5 \mathrm{Mb}$ flanking these loci were considered candidate genes for regulating FCR $[8,65]$. Then we used an omics knowledgebase, ISwine (http://iswine.iomics.pro), to search for candidate genes based on genome, transcriptome, quantitative traits and annotation information [20]. Transcriptome analyses in different tissues (muscle, liver, fat, hypothalamus) collected among 238 Yorkshire boars that with high or low FCR performances. These Yorkshire boars were castrated and fed in the fattening farms grown from 30 to $90 \mathrm{~kg}$ and the sample collection were performed in previous studies in our laboratory [14, 24, 39, 66]. Three high-FE pigs and three low-FE pigs that significantly differed were selected $(p<0.05)$ for RNA-seq. The detail information about the pigs used in RNA-seq was shown in Table S4. Total RNA was extracted from frozen muscle, fat, liver and hypothalamic tissues by using TRIzol reagent (Invitrogen, USA) and sent to Genergy Biotechnology (Shanghai, China) for library construction. Six RNA-seq libraries of muscle, fat, and liver tissues were constructed and applied for RNAseq. However, one of the high-FE samples failed to construct a library in hypothalamic tissues, and five RNAseq libraries (two high-FE libraries and three low-FE libraries) in hypothalamic tissues were used for RNA-seq. Salmon (version 1.4.0) was used to align sequencing reads to the pig reference genome Sscrofa 11.1 and for wicked-fast transcript quantification [67]. The negative binomial generalized liner models of DEseq2 was used to identify differentially expressed genes according to $\mid \log 2$ FoldChange $\mid(|\log 2 \mathrm{FC}|) \geq 1$ and $p$-value $<0.05$. Subsequently, the genes identified by ISwine and GWAS were integrated and analysed with the transcriptome results. Database for Annotation, Visualization and Integrated Discovery (DAVID) software (https://david. ncifcrf.gov/) was used for functional classification and pathway analysis for all the identified genes [68]. The differentially expressed genes identified by RNA-seq and the genes located in the QTL region associated with FCR were input into the DAVID software to found the genes located in the same signaling pathway.

\section{Abbreviations}

CNOT2: CCR4-NOT transcription complex subunit 2; DEBV: de-regressed estimated breeding values; FAR2: fatty acyl-CoA reductase 2; FCR: Feed conversion ratio; FRS2: fibroblast growth factor receptor substrate 2; GEBVs: genomic estimated breeding values; GRIP1: GLI pathogenesis related 1; GWAS: genome-wide association study; IRAK3: interleukin 1 receptor associated kinase 3; LD block: linkage disequilibrium block; MLMA: mixed linear model based association analysis; pigQTLdb: pig QTL database; QTL: quantitative trait locus: TIAM1; SNP: single nucleotide polymorphism; SSGBLUP: single-step genotype best linear unbiased prediction;

TPH2: tryptophan hydroxylase 2; TRHDE: thyrotropin releasing hormone degrading enzyme; YARS2: tyrosyl-tRNA synthetase 2; YY: Yorkshire pigs

\section{Supplementary Information}

The online version contains supplementary material available at https://doi. org/10.1186/s12864-021-07570-w.

Additional file 1: Table S1. Description of quantitative trait loci (QTL) in the regions significantly associated with FCR.

Additional file 2: Table S2. Summary information of significant SNPS and candidate genes for the FCR trait.

Additional file 3: Table S3. Candidate genes for FCR in pigs identified by the ISwine website.

Additional file 4: Table S4. Animal performance of Yorhshire pigs used in RNA sequencing.

Additional file 5: Table S5. List of hypothalamus DEGs between Yorkshire pigs with high and low FCR.

Additional file 6: Table S6. List of liver DEGs between Yorkshire pigs with high and low FCR.

Additional file 7: Table S7. List of muscle DEGs between Yorkshire pigs with high and low FCR.

Additional file 8: Table S8. List of fat DEGs between Yorkshire pigs with high and low FCR.

\section{Acknowledgements}

Thanks are due to Zhuqing Zheng for the help during the research.

\section{Authors' contributions}

Tao Xiang, Shuhong Zhao, Xinyun Li and Xuewen Xu conceived and designed the experiments; Yuanxin Miao, Quanshun Mei, Yan Liu and Chuanke Fu analyzed the data; Yuanxin Miao and Mingxing Liao contributed materials/analysis tools; Yuanxin Miao, Tao Xiang, Shuhong Zhao wrote the manuscript and all authors contributed to finalizing the writing. The authors read and approved the final manuscript.

\section{Funding}

This research was supported by the National Natural Science Foundation of China (31802039), the Fundamental Research Funds for the Central Universities (project number 2662020DKPY005), the Major Science and Technology Projects in Hubei Province (2020ABA016), the National Swine Industry Technology System (CARS-35), the Natural Science Foundation of Jingmen City (2020YFYB045), and the research fund from Jingchu University of Technology (QDJ201902).

\section{Availability of data and materials}

The datasets analyzed during the current study are available from the corresponding author upon request.

\section{Declarations}

\section{Ethics approval and consent to participate}

This study was approved by the Ethics Committee of Huazhong Agricultural University (HZAUMU2013-0005) following the recommendation of the Regulations for the Administration of Affairs Concerning Experimental Animals of China. All procedures involving tissue samples collection and animal care were performed according to the approved protocols and ARRIVE guidelines [69]. 


\section{Consent for publication}

Not applicable.

\section{Competing interests}

The authors declare no conflict of interest.

\section{Author details}

'Key Laboratory of Agricultural Animal Genetics, Breeding and Reproduction of Ministry of Education \& Key Laboratory of Swine Genetics and Breeding of Ministry of Agriculture, Huazhong Agricultural University, Wuhan 430070, China. ${ }^{2}$ The Cooperative Innovation Center for Sustainable Pig Production, Wuhan 430070, China. ${ }^{3}$ Jingchu University of Technology, Jingmen 448000, China. ${ }^{4}$ Agriculture and Rural Affairs Administration of Jingmen City, Jingmen 448000, China.

\section{Received: 26 November 2020 Accepted: 25 March 2021 Published online: 22 April 2021}

\section{References}

1. Patience JF, Rossoni-Serao MC, Gutierrez NA. A review of feed efficiency in swine: biology and application. J Anim Sci Biotechnol. 2015;6(1):33. https:// doi.org/10.1186/s40104-015-0031-2.

2. Saintilan R, Merour I, Brossard L, Tribout T, Dourmad JY, Sellier P, et al. Genetics of residual feed intake in growing pigs: relationships with production traits, and nitrogen and phosphorus excretion traits. J Anim Sci. 2013;91(6):2542-54. https://doi.org/10.2527/jas.2012-5687.

3. Gilbert H, Bidanel JP, Gruand J, Caritez JC, Billon Y, Guillouet P, et al. Genetic parameters for residual feed intake in growing pigs, with emphasis on genetic relationships with carcass and meat quality traits. J Anim Sci. 2007; 85(12):3182-8. https://doi.org/10.2527/jas.2006-590.

4. Beaulieu AD, Williams NH, Patience JF. Response to dietary digestible energy concentration in growing pigs fed cereal grain-based diets. J Anim Sci. 2009;87(3):965-76. https://doi.org/10.2527/jas.2007-0834.

5. Gilbert H, Bidanel JP, Billon $Y$, Lagant $H$, Guillouet $P$, Sellier $P$, et al. Correlated responses in sow appetite, residual feed intake, body composition, and reproduction after divergent selection for residual feed intake in the growing pig. J Anim Sci. 2012;90(4):1097-108. https://doi.org/1 0.2527/jas.2011-4515.

6. Ding R, Yang M, Wang X, Quan J, Zhuang Z, Zhou S, et al. Genetic architecture of feeding behavior and feed efficiency in a Duroc pig population. Front Genet. 2018;9:220. https://doi.org/10.3389/fgene.2018. 00220.

7. Horodyska J, Hamill RM, Varley PF, Reyer H, Wimmers K. Genome-wide association analysis and functional annotation of positional candidate genes for feed conversion efficiency and growth rate in pigs. PLoS One. 2017; 12(6):e0173482. https://doi.org/10.1371/journal.pone.0173482.

8. Do DN, Ostersen T, Strathe AB, Mark T, Jensen J, Kadarmideen HN. Genomewide association and systems genetic analyses of residual feed intake, daily feed consumption, backfat and weight gain in pigs. BMC Genet. 2014;15(1): 27. https://doi.org/10.1186/1471-2156-15-27.

9. Do DN, Strathe AB, Ostersen T, Pant SD, Kadarmideen HN. Genome-wide association and pathway analysis of feed efficiency in pigs reveal candidate genes and pathways for residual feed intake. Front Genet. 2014;5:307.

10. Bai C, Pan Y, Wang D, Cai F, Yan S, Zhao Z, et al. Genome-wide association analysis of residual feed intake in Junmu no. 1 white pigs. Anim Genet. 2017;48(6):686-90. https://doi.org/10.1111/age.12609.

11. Fan B, Lkhagvadorj S, Cai W, Young J, Smith RM, Dekkers JC, et al. Identification of genetic markers associated with residual feed intake and meat quality traits in the pig. Meat Sci. 2010;84(4):645-50. https://doi.org/1 0.1016/j.meatsci.2009.10.025.

12. Silva EF, Lopes MS, Lopes PS, Gasparino E. A genome-wide association study for feed efficiency-related traits in a crossbred pig population. Animal. 2019;13(11):2447-56. https://doi.org/10.1017/S1751731119000910.

13. Piorkowska K, Zukowski K, Tyra M, Szyndler-Nedza M, Szulc K, Skrzypczak E, et al. The Pituitary Transcriptional Response Related to Feed Conversion in Pigs. Genes. 2019;10:9.

14. Zhao Y, Hou Y, Liu F, Liu A, Jing L, Zhao C, et al. Transcriptome Analysis Reveals that Vitamin A Metabolism in the Liver Affects Feed Efficiency in Pigs. G3 (Bethesda). 2016;6(11):3615-24.

15. Liu C, Zhang $X$, Jing H, Miao $Y$, Zhao L, Han $Y$, et al. Research on drugreceptor interactions and prediction of drug activity via oriented immobilized receptor capillary electrophoresis. Electrophoresis. 2015;36(19): 2433-41. https://doi.org/10.1002/elps.201400583.

16. Messad F, Louveau I, Koffi B, Gilbert H, Gondret F. Investigation of muscle transcriptomes using gradient boosting machine learning identifies molecular predictors of feed efficiency in growing pigs. BMC Genomics. 2019;20(1):659. https://doi.org/10.1186/s12864-019-6010-9.

17. Tan Z, Wang Y, Yang T, Xing K, Ao H, Chen S, et al. Differentially expressed genes in the caecal and colonic mucosa of landrace finishing pigs with high and low food conversion ratios. Sci Rep. 2017;7(1):14886. https://doi. org/10.1038/s41598-017-14568-6.

18. Duggal P, Gillanders EM, Holmes TN, Bailey-Wilson JE. Establishing an adjusted $\mathrm{p}$-value threshold to control the family-wide type 1 error in genome wide association studies. BMC Genomics. 2008;9(1):516. https://doi. org/10.1186/1471-2164-9-516.

19. Hu ZL, Dracheva S, Jang W, Maglott D, Bastiaansen J, Rothschild MF, et al. A QTL resource and comparison tool for pigs: PigQTLDB. Mamm Genome. 2005;16(10):792-800. https://doi.org/10.1007/s00335-005-0060-9.

20. Fu Y, Xu J, Tang Z, Wang L, Yin D, Fan Y, et al. A gene prioritization method based on a swine multi-omics knowledgebase and a deep learning model. Commun Biol. 2020;3(1):502. https://doi.org/10.1038/s42003-020-01233-4.

21. Huangda W, Sherman BT, Lempicki RA. Systematic and integrative analysis of large gene lists using DAVID bioinformatics resources. Nat Protoc. 2009; 4(1):44-57.

22. bin Yusof MT, Kershaw MJ, Soanes DM, Talbot NJ. FAR1 and FAR2 regulate the expression of genes associated with lipid metabolism in the rice blast fungus Magnaporthe oryzae. PLoS One. 2014;9(6):e99760.

23. Burghardt KJ, Goodrich JM, Dolinoy DC, Ellingrod VL. Gene-specific DNA methylation may mediate atypical antipsychotic-induced insulin resistance. Bipolar Disord. 2016;18(5):423-32. https://doi.org/10.1111/bdi.12422.

24. Xu Y, Qi X, Hu M, Lin R, Hou Y, Wang Z, et al. Transcriptome analysis of adipose tissue indicates that the camp signaling pathway affects the feed efficiency of pigs. Genes. 2018;9:7.

25. Lee J, Karnuah AB, Rekaya R, Anthony NB, Aggrey SE. Transcriptomic analysis to elucidate the molecular mechanisms that underlie feed efficiency in meat-type chickens. Mol Gen Genomics. 2015;290(5):1673-82. https://doi. org/10.1007/s00438-015-1025-7.

26. Hulsmans M, Geeraert B, De Keyzer D, Mertens A, Lannoo M, Vanaudenaerde $B$, et al. Interleukin-1 receptor-associated kinase-3 is a key inhibitor of inflammation in obesity and metabolic syndrome. PLoS One. 2012;7(1):e30414. https://doi.org/10.1371/journal.pone.0030414.

27. Hulsmans M, Geeraert B, Arnould T, Tsatsanis C, Holvoet P. PPAR agonistinduced reduction of Mcp1 in atherosclerotic plaques of obese, insulinresistant mice depends on adiponectin-induced Irak3 expression. PLoS One. 2013;8(4):e62253. https://doi.org/10.1371/journal.pone.0062253.

28. Hulsmans M, Van Dooren E, Mathieu C, Holvoet P. Decrease of miR-146b-5p in monocytes during obesity is associated with loss of the antiinflammatory but not insulin signaling action of adiponectin. PLoS One. 2012;7(2):e32794. https://doi.org/10.1371/journal.pone.0032794.

29. Barbieri E, Sestili P. Reactive oxygen species in skeletal muscle signaling. J Signal Transduction. 2012;2012:982794.

30. Lee KP, Shin YJ, Cho SC, Lee SM, Bahn YJ, Kim JY, et al. Peroxiredoxin 3 has a crucial role in the contractile function of skeletal muscle by regulating mitochondrial homeostasis. Free Radic Biol Med. 2014;77:298-306. https:// doi.org/10.1016/j.freeradbiomed.2014.09.010.

31. Sommerville EW, Ng YS, Alston CL, Dallabona C, Gilberti M, He L, et al. Clinical features, molecular heterogeneity, and prognostic implications in YARS2-related mitochondrial myopathy. JAMA neurology. 2017;74(6):686-94. https://doi.org/10.1001/jamaneurol.2016.4357.

32. Riley LG, Heeney MM, Rudinger-Thirion J, Frugier M, Campagna DR, Zhou R, et al. The phenotypic spectrum of germline YARS2 variants: from isolated sideroblastic anemia to mitochondrial myopathy, lactic acidosis and sideroblastic anemia 2. Haematologica. 2018;103(12):2008-15. https://doi. org/10.3324/haematol.2017.182659.

33. Young JM, Cai W, Dekkers JC. Effect of selection for residual feed intake on feeding behavior and daily feed intake patterns in Yorkshire swine. J Anim Sci. 2011;89(3):639-47. https://doi.org/10.2527/jas.2010-2892.

34. Barea R, Dubois S, Gilbert H, Sellier P, van Milgen J, Noblet J. Energy utilization in pigs selected for high and low residual feed intake. J Anim Sci. 2010;88(6):2062-72. https://doi.org/10.2527/jas.2009-2395.

35. Herd RM, Arthur PF. Physiological basis for residual feed intake. J Anim Sci. 2009;87(14 Suppl):E64-71. https://doi.org/10.2527/jas.2008-1345. 
36. Wu Q, Palmiter RD. GABAergic signaling by AgRP neurons prevents anorexia via a melanocortin-independent mechanism. Eur J Pharmacol. 2011;660(1): 21-7. https://doi.org/10.1016/j.ejphar.2010.10.110.

37. Morton GJ, Cummings DE, Baskin DG, Barsh GS, Schwartz MW. Central nervous system control of food intake and body weight. Nature. 2006; 443(7109):289-95. https://doi.org/10.1038/nature05026.

38. Delgado TC. Glutamate and GABA in appetite regulation. Front Endocrinol. 2013;4:103.

39. Hou Y, Hu M, Zhou H, Li C, Li X, Liu X, et al. Neuronal signal transductioninvolved genes in pig hypothalamus affect feed efficiency as revealed by Transcriptome analysis. Biomed Res Int. 2018;2018:5862571.

40. Lee JB, Park HB, Yoo CK, Kim HS, Cho IC, Lim HT. Association of a missense mutation in the positional candidate gene glutamate receptor-interacting protein 1 with backfat thickness traits in pigs. Asian Australas J Anim Sci. 2017;30(8):1081-5. https://doi.org/10.5713/ajas.16.0414.

41. Reyer H, Oster M, Magowan E, Murani E, Sauerwein H, Dannenberger D, et al. Feed-efficient pigs exhibit molecular patterns allowing a timely circulation of hormones and nutrients. Physiol Genomics. 2018;50(9):726-34. https://doi.org/10.1152/physiolgenomics.00021.2018.

42. Xi TF, Li DN, Li YY, Qin Y, Wang HH, Song NN, et al. Central 5hydroxytryptamine $(5-H T)$ mediates colonic motility by hypothalamus oxytocin-colonic oxytocin receptor pathway. Biochem Biophys Res Commun. 2019;508(3):959-64. https://doi.org/10.1016/j.bbrc.2018.11.122.

43. Li Z, Yang HY, Wang Y, Zhang ML, Liu XR, Xiong Q, et al. Generation of tryptophan hydroxylase 2 gene knockout pigs by CRISPR/Cas9-mediated gene targeting. J Biomed Res. 2017;31(5):445-52. https://doi.org/10.7555/ JBR.31.20170026.

44. van Lingen M, Sidorova M, Alenina N, Klempin F. Lack of brain serotonin affects feeding and differentiation of newborn cells in the adult hypothalamus. Front Cell Dev Biol. 2019;7:65. https://doi.org/10.3389/fcell.2 019.00065 .

45. Brent GA. Mechanisms of thyroid hormone action. J Clin Invest. 2012;122(9): 3035-43. https://doi.org/10.1172/JCl60047.

46. Tata JR. The road to nuclear receptors of thyroid hormone. Biochim Biophys Acta. 2013;1830(7):3860-6. https://doi.org/10.1016/j.bbagen.2012.02.017.

47. Mullur R, Liu YY, Brent GA. Thyroid hormone regulation of metabolism. Physiol Rev. 2014;94(2):355-82. https://doi.org/10.1152/physrev.00030.2013.

48. Williams GR. Neurodevelopmental and neurophysiological actions of thyroid hormone. J Neuroendocrinol. 2008;20(6):784-94. https://doi.org/10.1111/j.13 65-2826.2008.01733.x.

49. Paul BD, Shi YB. Distinct expression profiles of transcriptional coactivators for thyroid hormone receptors during Xenopus laevis metamorphosis. Cell Res. 2003;13(6):459-64. https://doi.org/10.1038/sj.cr.7290188.

50. Hayashi M, Futawaka K, Matsushita M, Hatai M, Yoshikawa N, Nakamura K, et al. Cigarette smoke extract disrupts transcriptional activities mediated by thyroid hormones and its receptors. Biol Pharm Bull. 2018;41(3):383-93. https://doi.org/10.1248/bpb.b17-00735.

51. Videla LA, Vargas R, Riquelme B, Fernandez J, Fernandez V. Thyroid Hormone-Induced Expression of the Hepatic Scaffold Proteins Sestrin2, beta-Klotho, and FRS2alpha in Relation to FGF21-AMPK Signaling. Exp Clin Endocrinol Diabetes. 2018;126(3):182-6.

52. Alesi V, Loddo S, Cali F, Orlando V, Genovese S, Ferretti D, et al. A heterozygous, intragenic deletion of CNOT2 recapitulates the phenotype of 12q15 deletion syndrome. Am J Med Genet A. 2019;179(8):1615-21. https:// doi.org/10.1002/ajmg.a.61217.

53. Arora R, Naveen Kumar S, Fairoze MN, Kaur M, Sharma A, Girdhar Y, et al. Transcriptome profiling of longissimus thoracis muscles identifies highly connected differentially expressed genes in meat type sheep of India. PLoS One. 2019;14(6):e0217461. https://doi.org/10.1371/journal.pone.0217461.

54. Schomburg L, Turwitt S, Prescher G, Lohmann D, Horsthemke B, Bauer K. Human TRH-degrading ectoenzyme cDNA cloning, functional expression, genomic structure and chromosomal assignment. Eur J Biochem. 1999; 265(1):415-22. https://doi.org/10.1046/j.1432-1327.1999.00753.x.

55. Freudenberg J, Lee HS, Han BG, Shin HD, Kang YM, Sung YK, et al. Genomewide association study of rheumatoid arthritis in Koreans: populationspecific loci as well as overlap with European susceptibility loci. Arthritis Rheum. 2011;63(4):884-93. https://doi.org/10.1002/art.30235.

56. Zhang L, Ma X, Xuan J, Wang H, Yuan Z, Wu M, et al. Identification of MEF2B and TRHDE gene polymorphisms related to growth traits in a new Ujumqin sheep population. PLoS One. 2016;11(7):e0159504. https://doi.org/1 0.1371/journal.pone.0159504.
57. Groenen MA, Archibald AL, Uenishi H, Tuggle CK, Takeuchi Y, Rothschild MF, et al. Analyses of pig genomes provide insight into porcine demography and evolution. Nature. 2012;491(7424):393-8. https://doi.org/10.1038/na ture11622.

58. Legarra A, Aguilar I, Misztal I. A relationship matrix including full pedigree and genomic information. J Dairy Sci. 2009;92(9):4656-63. https://doi.org/1 0.3168/jds.2009-2061.

59. Christensen OF, Lund MS. Genomic prediction when some animals are not genotyped. Genet Sel Evol. 2010;42(1):2. https://doi.org/10.1186/12979686-42-2.

60. Ostersen T, Christensen OF, Henryon M, Nielsen B, Su G, Madsen P. Deregressed EBV as the response variable yield more reliable genomic predictions than traditional EBV in pure-bred pigs. Genet Sel Evol. 2011; 43(1):1297-9686.

61. Garrick DJ, Taylor JF, Fernando RL. Deregressing estimated breeding values and weighting information for genomic regression analyses. Genet Sel Evol. 2009;41(1):55. https://doi.org/10.1186/1297-9686-41-55.

62. Sevillano CA, Lopes MS, Harlizius B, Hanenberg EH, Knol EF, Bastiaansen JW. Genome-wide association study using deregressed breeding values for cryptorchidism and scrotal/inguinal hernia in two pig lines. Genet Sel Evol. 2015;47(1):015-0096

63. Yang J, Lee SH, Goddard ME, Visscher PM. GCTA: a tool for genome-wide complex trait analysis. Am J Hum Genet. 2011;88(1):76-82. https://doi.org/1 0.1016/j.ajhg.2010.11.011

64. Barrett JC, Fry B, Maller J, Daly MJ. Haploview: analysis and visualization of LD and haplotype maps. Bioinformatics. 2005;21(2):263-5. https://doi.org/1 0.1093/bioinformatics/bth457.

65. Sahana G, Kadlecova V, Hornshoj H, Nielsen B, Christensen OF. A genomewide association scan in pig identifies novel regions associated with feed efficiency trait. J Anim Sci. 2013;91(3):1041-50. https://doi.org/10.2527/jas.2 012-5643.

66. Jing L, Hou Y, Wu H, Miao Y, Li X, Cao J, et al. Transcriptome analysis of mRNA and miRNA in skeletal muscle indicates an important network for differential residual feed intake in pigs. Sci Rep. 2015;5(1):11953. https://doi. org/10.1038/srep11953.

67. Patro R, Duggal G, Love MI, Irizarry RA, Kingsford C. Salmon provides fast and bias-aware quantification of transcript expression. Nat Methods. 2017; 14(4):417-9. https://doi.org/10.1038/nmeth.4197.

68. Dennis G Jr, Sherman BT, Hosack DA, Yang J, Gao W, Lane HC, et al. DAVID: database for annotation, visualization, and integrated discovery. Genome Biol. 2003;4(5):3. https://doi.org/10.1186/gb-2003-4-9-r60.

69. Percie du Sert N, Ahluwalia A, Alam S, Avey MT, Baker M, Browne WJ, et al. Reporting animal research: Explanation and elaboration for the ARRIVE guidelines 2.0. PLoS Biol. 2020;18(7):e3000411.

\section{Publisher's Note}

Springer Nature remains neutral with regard to jurisdictional claims in published maps and institutional affiliations.

Ready to submit your research? Choose BMC and benefit from:

- fast, convenient online submission

- thorough peer review by experienced researchers in your field

- rapid publication on acceptance

- support for research data, including large and complex data types

- gold Open Access which fosters wider collaboration and increased citations

- maximum visibility for your research: over $100 \mathrm{M}$ website views per year

At $\mathrm{BMC}$, research is always in progress.

Learn more biomedcentral.com/submissions 